\title{
Input shaping control of a flexible cantilever beam excited by a moving hub
}

\author{
Nguyen Tri Giang Vu ${ }^{1}$, Phuong Tung Pham ${ }^{2}$, Quoc Chi Nguyen ${ }^{1, *}$
}

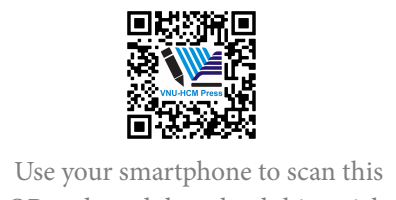

QR code and download this article

${ }^{1}$ The Department of Mechatronics, Ho Chi Minh City University of

Technology-Vietnam National University at Ho Chi Minh City

${ }^{2}$ Mechanical Engineering, Pusan National University

Correspondence

Quoc Chi Nguyen, The Department of Mechatronics, Ho Chi Minh City University of Technology-Vietnam National University at Ho Chi Minh City

Email: nqchi@hcmut.edu.vn

History

- Received: 01-10-2019

- Accepted: 30-01-2020

- Published: 16-8-2020

DOI :10.32508/stdjet.v3i2.605

\section{Check for updates}

Copyright

(c) VNU-HCM Press. This is an openaccess article distributed under the terms of the Creative Commons Attribution 4.0 International license.

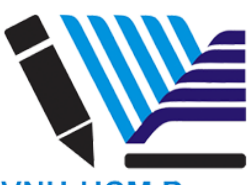

VNU-HCM Press

\begin{abstract}
Introduction: A cantilever beam is a well-known structural element in engineering, which is only fixed at one end. This structure can be used to describe a manipulator, whose stiffness is large to ensure rigidity and stability of the system. A flexible cantilever beam provides a light-weight structure and high cost efficiency but generates vibration under high-speed positioning. In this paper, we aim to control the vibratory behavior of a flexible cantilever beam attached to a moving hub. Method: The mathematical model of the flexible beam is described by partial differential equations (PDEs) using Euler-Bernoulli beam theory. Then, The PDE model is approximated by using the Galerkin method, which is resulted in a set of ordinary differential equations (ODEs). Experiment is used to determine unknown parameters of the system to complete the model. The ODE model enables the control design of three input shapers: (i) Zero-Vibration (ZV), (ii) Zero-Vibration-Derivative (ZVD), and (iii) Zero-Vibration-Derivative-Derivative (ZVDD), which are employed to drive the flexible beam to the desired position and to reduce vibrations of the beam. Results and conclusion: The dynamic model is obtained in term of ordinary differential equations. Unknown parameters of the system are determined by experimental process. Various controllers are designed to eliminate the vibration of the beam. The simulation is applied to predict the dynamic response of the beam to verify the designed controllers numerically. Experiment shows the validity of the mathematical model through the consistency between the simulation and experimental data and the effectiveness of the controllers for the real system. These controllers show several advantages such as no need of extra equipment; the positioning controller is intact, which means it may be applied to many existing systems.

Key words: Flexible cantilever beam, Galerkin method, input shaping, vibration suppression
\end{abstract}

\section{INTRODUCTION}

Conventional manipulators are constructed by rigid links with large stiffness to ensure accuracy of end effectors, and therefore, leading to heavy manipulators. Power efficiency is low due to the high weight manipulators. It has been shown that lightweight manipulators can yield cost efficiency. However, lightweight manipulators that can be considered as flexible manipulators generate the vibration problems (especially in high-speed manipulators), and consequently the inaccuracy of the end effectors. Therefore, the development of a control algorithm that allows fast motion with high accuracy and quick vibration suppression is desirable for flexible manipulators. In this paper, we first develop the control algorithm for a singlelink flexible manipulator, which can be considered as a flexible cantilever beam system.

It is desirable to obtain dynamic models of a flexible beam, namely two well-known theories of EulerBernoulli $^{1-10}$ and Timoshenko ${ }^{11-13}$. In detail, the Euler-Bernoulli theory was developed in the $18^{\text {th }}$ century, which contributed to a simple linear theory of elasticity. It comprised lateral deflection of beams and thus still widely applied, especially in vibration suppression of beams. Timoshenko considered shear deformation and rotational bending, which were neglected in the Euler-Bernoulli theory, resulted in equations of $4^{\text {th }}$ order. Dynamics models derived from the mentioned theories are represented by PDEs by using Hamilton's principle ${ }^{2,10}$, which have no solutions in some cases, especially in the case of nonlinear PDEs. Therefore, the control design for the dynamic systems based on PDEs encounter difficulties because of the infinite dimension of the dynamic model. To overcome the challenge, the PDEs can be approximated by a finite-dimensional set of ODEs ${ }^{2,14,15}$, which possesses finite order. The approximation methods can be listed as the Galerkin method $^{14,15}$ and the finite element method ${ }^{2}$.

Although flexible structures have shown their advantages, it is difficult to control in comparison with rigid ones. Control techniques can be sorted into feedback and feedforward controls. In the field of feedback 
control, positive position feedback (PPF) was applied on the Euler-Bernoulli beam by using a piezoelectric actuator $^{16}$, while strain rate feedback (SRF) controller was used by Fei ${ }^{17}$. Both PPF and SRF control algorithms are essentially second-order compensators to vary damping ratio and stiffness of the system called active damping and active stiffness, respectively. A robust control scheme was presented by Aphale et al. ${ }^{18}$, where a modification of system transfer function allowed integral feedback generating improvement of performance. Omidi et al. ${ }^{19}$ Multi positive feedback (MPF), which included feedback signals of position and velocity to suppress vibrations. Feedback control requires the installation of extra actuators and/or sensors, which may not be implemented in practice (for example, in machining tools).

In contrast to feedback control, feedforward control that does not require feedback signals also attracts many researchers. In a cost-effectiveness point of view, the feedforward control is more advantageous than the feedback control because of ignoring sensors. Singer et al. ${ }^{20}$ developed a new feedforward technique, i.e., preshaped command, based on the characteristics of control objects, called ZV shaper. However, ZV shaper is insufficient for most systems due to its insensitiveness of modeling error. Additional constraint equations were used to overcome this problem, which created ZVD shaper and ZVDD shaper based on added derivative constraints ${ }^{21}$. An alternative robustness shaper was known as Extra-Insensitive (EI) shaper, which was used by Singhose et al. ${ }^{22}$ to put residual vibration into acceptable tolerance while the derivative of residual vibration converged to zero. Nguyen et al. ${ }^{23}$ designed the input shaping control to minimize the vibration of a rotational beam. SadatHoseini et al. ${ }^{24}$ derived an optimal-integral feedforward control scheme to control vibrations of aircraft wings enabling the auto-landing of aircraft. Zhu et al. $^{25}$, an adaptive feedforward control scheme was proposed to suppress vibrations of a cantilever beam with unknown multiple frequencies. Sahinkaya ${ }^{26} \mathrm{de}-$ veloped a method, which is based on inverse dynamics, to generate shaped inputs for a lightly damped system. Physik Instrumente company introduced a vibration suppression solution including hardware (a controller is compatible with linear motors) and software that is based on input shaping method ${ }^{27}$.

It is shown that the control of the flexible beam not been focused by researchers. In this paper, input shapers (ZV, ZVD, and ZVDD) are applied to suppress the vibration of a translational flexible cantilever beam while the beam moves to the desired position.
An experiment system is conducted to verify the effectiveness of the controller. The motion controller is implemented by UMAC manufactured by Delta Tau, and the linear actuators Yokogawa is employed to generate the command shaping input for the motion of the flexible beam system.

This paper is organized as follows. In Section 2, the model formulation of translating flexible beam system is presented. Section 3 proposes input shapers. In Section 4, simulations and experiments are shown. In Section 5, the conclusions are made.

\section{PROBLEM FORMULATION}

In this paper, the dynamics of a flexible cantilevered beam system that is shown in Figure 1 is investigated. Let $M$ be mass attached to the tip of the beam, $m$ be the mass of the moving hub, and $L$ is the length of the beam. The parameters of the beam are $r$ is the mass per unit length; EI is defined as flexural rigidity. The hub moves in the $X O Y$ plane. In this paper, the hub's translational motion takes place along the fixed $X_{1}$ axis, where the angle $\theta$ between $X_{1}$-axis and $X$-axis is constant. It is shown that the deformation of the beam in thed plane $X_{1} O Y$.

The governing equation and boundary conditions of the flexible beam system (see Figure 1) are given as follows ${ }^{28}$.

$$
\rho(\ddot{\alpha}+\ddot{w})+E I w^{I V}=0,
$$

$$
m \ddot{\alpha}+\int_{0}^{L} \rho(\ddot{\alpha}+\ddot{w}(z, t)) d z+M(\ddot{\alpha}+\ddot{w}(L, t))=f(t),
$$

with the boundary conditions:

$$
\begin{aligned}
& z=0, w=0, w^{\prime}=0, \\
& z=L, E L w^{\prime \prime \prime}-M(\ddot{w}+\ddot{\alpha})=0, w^{\prime \prime}=0 .
\end{aligned}
$$

In Eq. (1), $\alpha$ is the movement of the hub, and $w(z, t)$ is an elastic at time $t$. The excitation force $f(t)$ applied to the beam.

By applying the Galerkin method, the discrete model that is the approximation of the continuous model Eqs. (1)-(3) is obtained as follows.

$$
\begin{gathered}
\mathbf{M} \ddot{\triangle}+\mathbf{C} \dot{\triangle}+\mathbf{K} \triangle=\mathbf{F} u(t), \\
\mathbf{M}=\left[\begin{array}{ccccc}
J & E_{1} & E_{2} & \ldots & E_{n} \\
E_{1} & M_{11} & M_{12} & \ldots & M_{1 n} \\
E_{2} & M_{21} & M_{22} & \ldots & M_{2 n} \\
\vdots & \vdots & \vdots & \ddots & \vdots \\
E_{n} & M_{n 1} & M_{n 2} & \ldots & M_{n n}
\end{array}\right],
\end{gathered}
$$



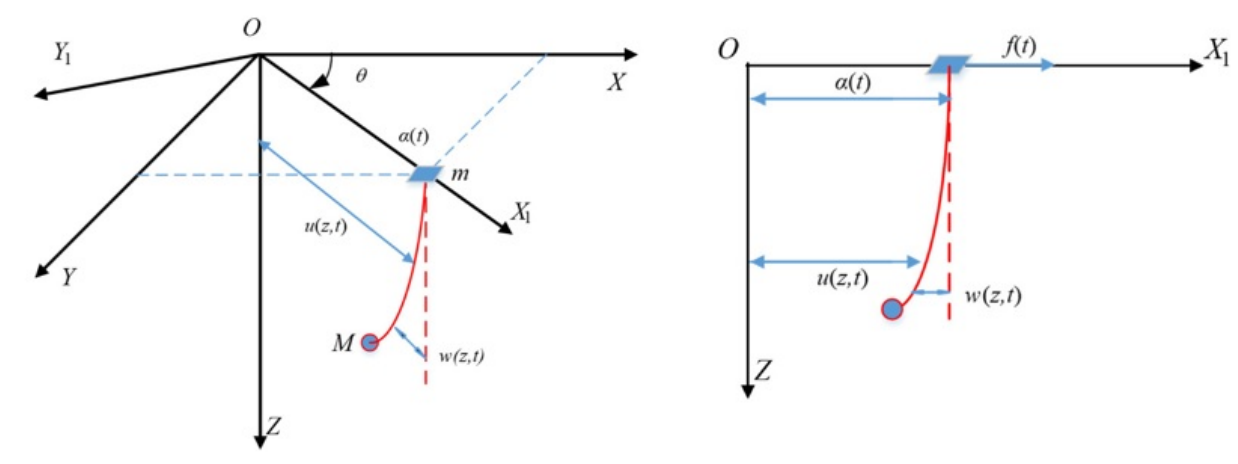

Figure 1: The cantilever beam with translational hub in three-dimensional space.

$$
\begin{aligned}
\mathbf{K} & =\left[\begin{array}{ccccc}
0 & 0 & 0 & \ldots & 0 \\
0 & K_{11} & K_{12} & \ldots & K_{1 n} \\
0 & K_{21} & K_{22} & \ldots & K_{2 n} \\
\vdots & \vdots & \vdots & \ddots & \vdots \\
0 & K_{n 1} & K_{n 2} & \ldots & K_{n n}
\end{array}\right], \\
\triangle & =\left[\begin{array}{c}
\alpha \\
q_{1} \\
q_{2} \\
\vdots \\
q_{n}
\end{array}\right], \mathbf{F}=\left\{\begin{array}{c}
1 \\
0 \\
0 \\
\vdots \\
0
\end{array}\right\}, u=f(t) .
\end{aligned}
$$

The matrix element $M_{i j}$ and $K_{i j}$ in Eqs. (5) and (6) are given as:

$$
\begin{gathered}
M_{i j}=\rho \int_{0}^{L} \varphi_{i} \varphi_{j} d z+M \varphi_{i}(L) \varphi_{j}(L), \\
K_{i j}=E I \int_{0}^{L} \varphi_{i}^{\prime \prime} \varphi_{j}^{\prime \prime} d z .
\end{gathered}
$$

\section{INPUT SHAPING CONTROL METHOD}

In this section, an input shaping control with a twoimpulse sequence is designed. The control goal is to cancel oscillations of the cantilever beam while the hub moves to the desired position.

Input shaping is feedforward control, in which a shaped command is achieved by convolving a sequence of impulses. The impulse response of any vibratory order system can be indicated as a series of second-order functions $\left[{ }^{29}\right.$, pp. 1071]. Its expression in the time domain is:

$$
\begin{aligned}
& y(t)= \\
& {\left[A \frac{\omega_{0}}{\sqrt{1-\zeta^{2}}} e^{-\zeta \omega_{0}\left(t-t_{0}\right)}\right] \sin \left(\omega_{0} \sqrt{1-\zeta^{2}}\left(t-t_{0}\right)\right),}
\end{aligned}
$$

where $A$ and $t_{0}$ are the amplitude and the occurrence time of the impulse, respectively. The principle of input shaping technique is illustrated in Figure 2. When the first impulse is exerted on the system, it produces a vibration with amplitude (solid line). After a one-half period, it is superposed to cause an opposite vibration (dash line). As a result, two impulses cancel each other to obtain the vibration-free system (dot line).

From Eq. (10), the vibration amplitude for a multipleimpulse input is obtained as follows ${ }^{20}$.

$$
\begin{aligned}
& A_{a m p}= \\
& \sqrt{\left(\sum_{j=1}^{N} B_{j} \cos \phi_{j}\right)^{2}+\left(\sum_{j=1}^{N} B_{j} \sin \phi_{j}\right)^{2}}
\end{aligned}
$$

where

$$
\phi_{1}=\omega \sqrt{\left(1-\zeta^{2}\right) t_{j}}
$$

Vibration suppression requires $A_{a m p}$ is zero when the input completes. By solving these conditions, the vibration-free solution could be obtained. The basic shaper is called as zero vibration $(\mathrm{ZV})$ :

$$
\left[\begin{array}{c}
A_{j} \\
t_{j}
\end{array}\right]=\left[\begin{array}{cc}
\frac{1}{1+K} & \frac{K}{1+K} \\
0 & 0.5 T_{d}
\end{array}\right] .
$$

From Eq. (13), the ZV shaper requires the system's natural frequency and damping, which can be obtained by experiment or computation. In this research, these two parameters of the flexible beam are derived from experiments (see Section 4 for details). The vibration suppression technique above is effective only if system parameters are exactly known. Some constraints have been made to make the shaper insensitive to modeling error. The key idea in ${ }^{20}$ is to take vibration error into an account to achieve robustness with respect to modeling error of the natural frequency. Let the derivative of vibration error equals to 


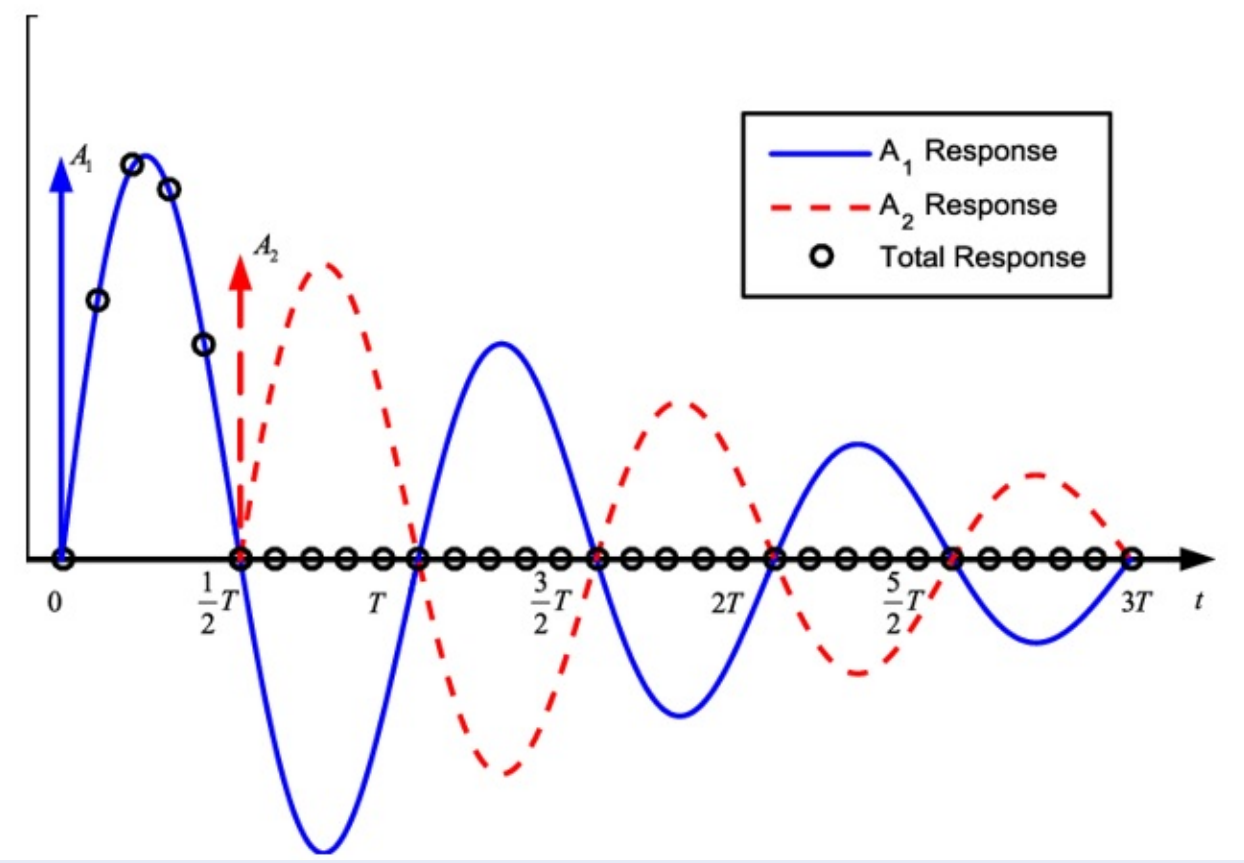

Figure 2: Schematic diagram of the input shaping method.

zero, the ZVD shaper is obtained as follows:

$$
\left[\begin{array}{c}
A_{j} \\
t_{j}
\end{array}\right]=\left[\begin{array}{ccc}
\frac{1}{J_{Z V D}} & \frac{2 K}{J_{Z V D}} & \frac{K^{2}}{J_{Z V D}} \\
0 & 0.5 T_{d} & T_{d}
\end{array}\right]
$$

where

$J_{Z V D}=1+2 K+K^{2}$.

\section{SIMULATION AND EXPERIMENTAL RESULTS}

The model of the flexible beam Eqs. (4)-(9) established in Section 2 is used to simulate the dynamics of the beam, whose parameters are listed in Table 1. These parameters are both used in simulation processes and experiments. It should be noted that, in this research, the tip mass is neglected in the control design of input shapers.

The behaviors of the flexible beam are simulated with three commands: (i) The unshaped command is an Scurve profile with a displacement of $50 \mathrm{~mm}$ in $0.1 \mathrm{~s}$; (ii) ZV, ZVD, and ZVDD shapers are implemented to compare the performance of each shaper.

As shown in Figure 3, the unshaped command causes a large vibration of the tip, which takes a long time for suppression. In the case of shaped command, the $\mathrm{ZV}$ shaper achieves the settling time is 0.5 seconds when the tolerance band $5 \%$ is applied. ZVD shaper shows better performance compared to the $\mathrm{ZV}$ shaper when the amplitude of the vibration is significantly reduced. Finally, the ZVDD shaper obtained the best performance with zero vibration after 0.4 seconds.

\begin{tabular}{lll}
\multicolumn{2}{l}{ Table 1: System Parameters } \\
\hline Symbol & Definition & Values \\
$L$ & Beam length & $0.45 \mathrm{~m}$ \\
$h$ & Beam height of area & $28.8 \times 10^{-3} \mathrm{~m}$ \\
$b$ & Beam width of area & $0.88 \times 10^{-3} \mathrm{~m}$ \\
$\rho$ & Beam linear density & $0.2 \mathrm{~kg} \cdot \mathrm{m}^{-1}$ \\
$E I$ & Beam flexural rigidity & $332.714 \times 10^{-3}$ \\
& & $\mathrm{Nm}^{2}$ \\
$m$ & Mass of hub & $1.5 \mathrm{~kg}$ \\
\hline
\end{tabular}

The experiments are carried out in this research. The testbed and data acquisition are shown in Figure 4. The system consists of one single translational DOF, whose link is a flexible aluminum beam. One beam's end is fixed rigidly to a brushless linear motor while the other end is free.

In the experiment system, an LM series linear servo motor from Yokogawa performs movements directly. This feature brings many advantages, the motor's velocity and the ratio of thrust to weight are significantly large $\left(0.8 \mathrm{~m} / \mathrm{s}\right.$, and $7 \mathrm{~m} / \mathrm{s}^{2}$, respectively). Also, the positioning precision of the fixed end's link is equal to the 


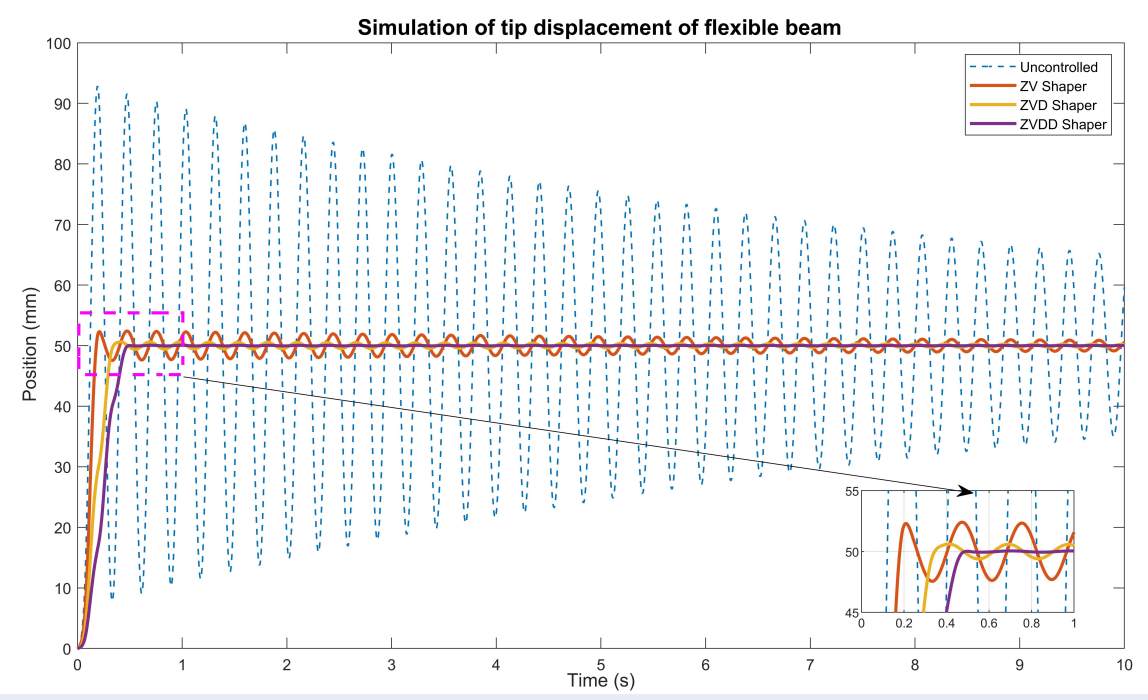

Figure 3: Simulation results of the tip displacement of the flexible beam.

servo motor's precision $(0.5 \mu \mathrm{m})$ due to backlash absence. These factors contribute to high performance of the whole system. The motor is powered by TM series servo amplifier from Yokogawa. The command is fed by a motion control unit, which is Turbo Compact UMAC CPU from Delta Tau . With Motorola DSPs Processor, the Turbo CPU is a powerful motion controller that provides a packed combination of motion and I/O control for a complex automatic system. The integrated features include trajectory generation, servo, commutation, compensation, motion program, and so forth. The damping ratio is obtained by logarithmic decrement $\delta$ which is defined as the natural log of the ratio of any two successive peaks. This method is conducted through the result of the experiment on the underdamped vibration of the beam (see Figure 5).

The logarithmic decrement $\delta$ is presented as

$$
\delta=\frac{1}{n} \ln \left(\frac{x_{i}}{x_{i+n}}\right)=\ln \left(\frac{33.19}{31.67}\right)=0.047
$$

The damping ratio, then, determined by the relationship with logarithmic decrement as follows:

$$
\zeta=\frac{\delta}{\sqrt{\delta^{2}+4 \pi^{2}}}=0.0075
$$

The natural frequency is determined by plotting the frequency spectrum (Figure 6) of the free vibration of the beam with initial disturbance.

The experimental results are shown in Figure 7, it is shown that experimental data is consistent with predicted results. With the unshaped command, the vibrations of the flexible beam occur for a long time.
Meanwhile, the ZV, ZVD, and ZVDD shapers eliminate vibrations significantly. The simple ZV shaper reduces a large vibration of $9 \%$ compared to unshaped command while the vibration of ZVD and ZVDD shapers are both lower than $2 \%$ in relation to unshaped command.

\section{DISCUSSIONS AND CONCLUSION}

In this paper, three input shapers $\mathrm{ZV}, \mathrm{ZVD}$, and ZVDD for the simultaneous position and vibration control of a flexible cantilever beam excited by a moving hub are proposed. The design of input shapers is based on the ODE model of the flexible beam system, which is derived by using the Galerkin method. The validity of the proposed input shapers is verified by both simulations and experiments.

\section{ACKNOWLEDGEMENT}

This work was supported T-CK-2018-07.

\section{LIST OF ABBREVIATIONS USED}

PDE: Partial differential equation ODE: Ordinary differential equation

ZV: Zero vibration

ZVD: Zero vibration derivative

ZVDD: Zero vibration derivative derivative

PPF: positive position feedback

SRF: strain rate feedback

\section{COMPETING INTERESTS}

The authors declare that they have no conflicts of interest. 


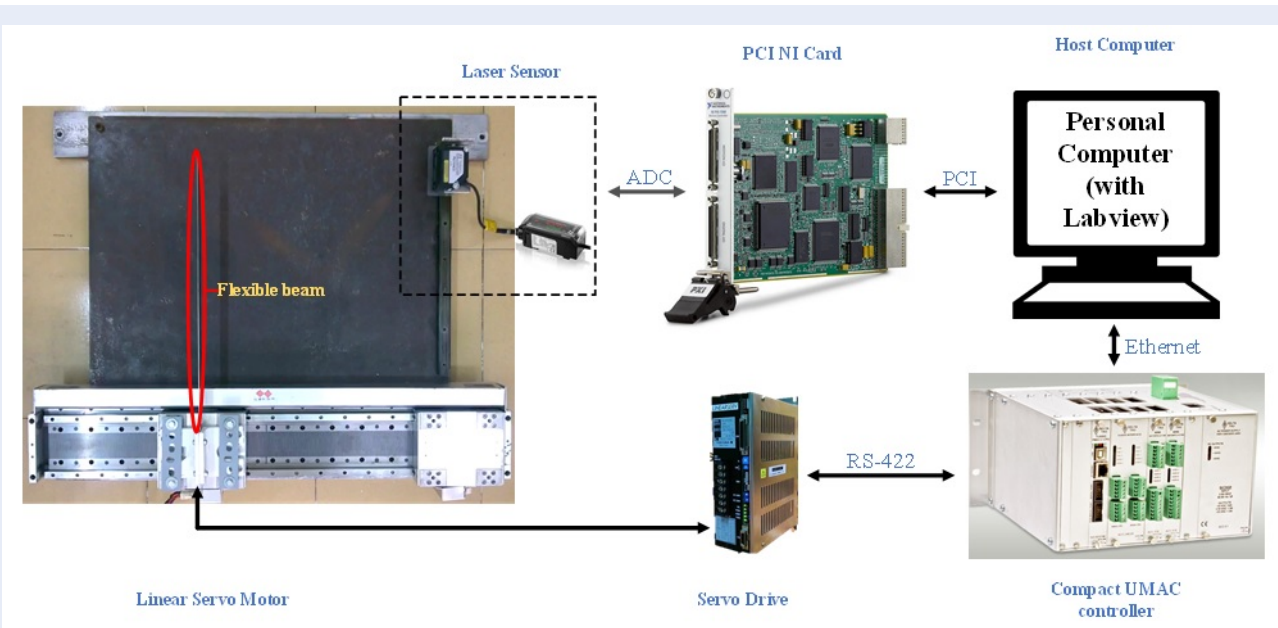

Figure 4: Experimental testbed.

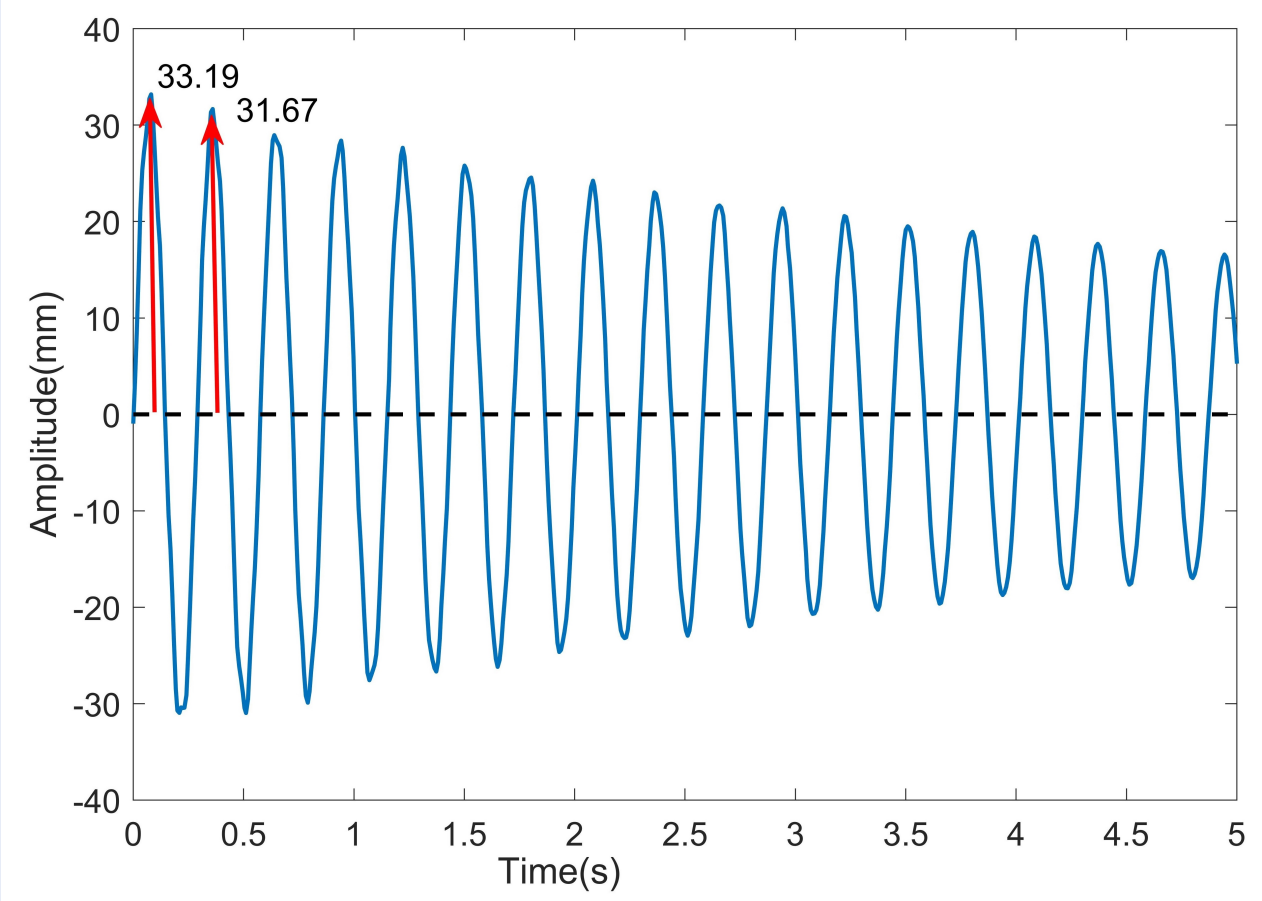

Figure 5: Free vibration of a viscous damped cantilever beam. 


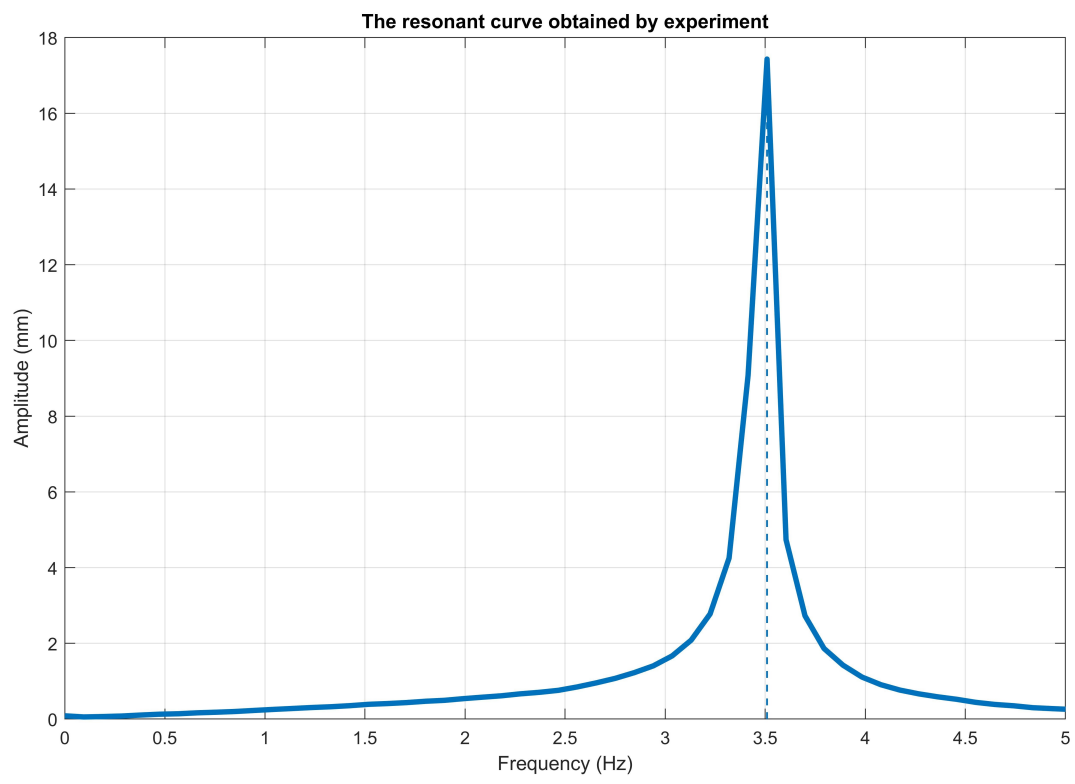

Figure 6: The experimental frequency spectrum of the beam.

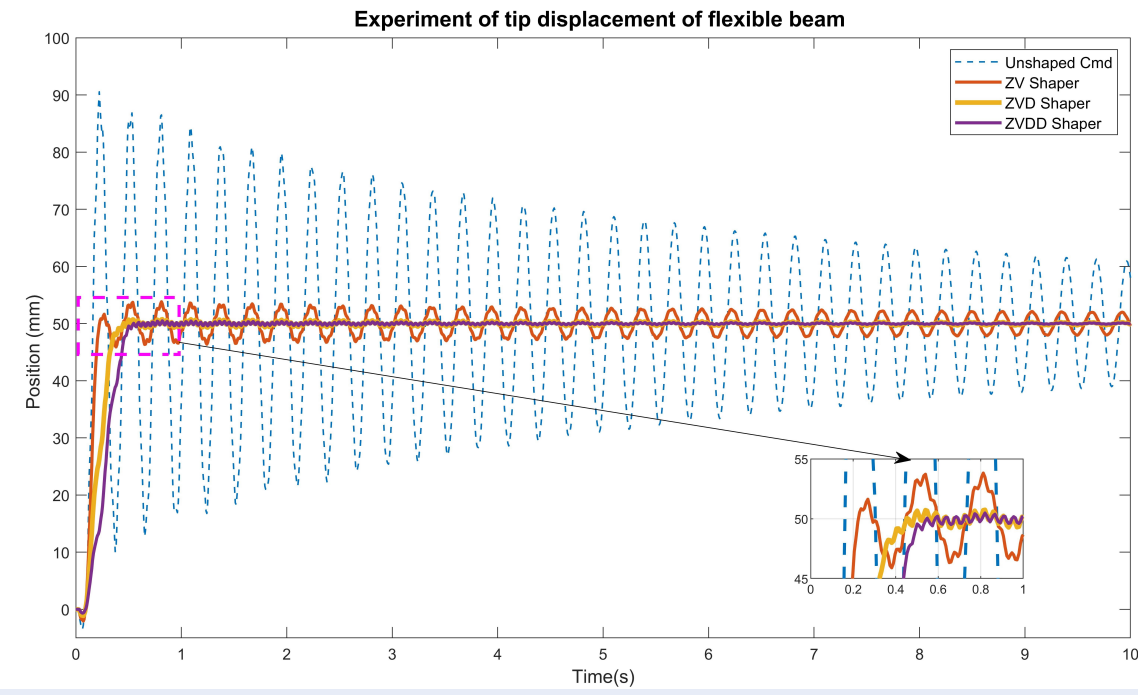

Figure 7: Experimental results shows the displacements of the flexible beam in uncontrolled case and with controlled cases (with ZV, ZVD, and ZVDD shaper). 


\section{AUTHOR CONTRIBUTION}

Nguyen Tri Giang Vu has deisgned the controller for simulation and experiment purposes and has written the manuscript. Phuong Tung Pham has investigated the dynamic model and has examined the initial experiment. Quoc Chi Nguyen has provided research ideas, has guided the research and has edited the manuscript.

\section{REFERENCES}

1. Paranjape AA, Guan J, Krstic M. PDE boundary control for flexible articulated wings on a robotics aircraft. IEEE Transactions on Robotics. 2013;29(3):625-640. Available from: https: //doi.org/10.1109/TRO.2013.2240711.

2. Yang JB, Jiang LJ, Chen DC. Dynamic modelling and control of a rotating Euler-Bernoulli beam. Journal of Sound and Vibration. 2004;274(3-5):863-875. Available from: https://doi.org/ 10.1016/S0022-460X(03)00611-4.

3. Kane TR, Ryan RR. Dynamics of a cantilever beam attached to a moving base. Journal of Guidance, Control, and Dynamics. 1987;10(2):139-151. Available from: https://doi.org/10.2514/ 3.20195 .

4. What is citation 4 ?;

5. Park S, Chung WK, Youm Y, Lee JW. Natural frequencies and open-loop responses of an elastic beam fixed on a moving cart and carrying an intermediate lumped mass. Journal of Sound and Vibration. 2000;230(3):591-615. Available from: https://doi.org/10.1006/jsvi.1999.2631.

6. Patil O, Gandhi P. On the dynamics and multiple equilibria of inverted flexible pendulum with tip mass on cart. Journal of Dynamic Systems, Measurement, and Control. 2014;136(4):041017-041017-9. Available from: https://doi. org/10.1115/1.4026831.

7. Hayase T, Yoshikazu S. Control of a flexible inverted pendulum. Advanced Robotics. 1994;8(1):1-12. Available from: https://doi.org/10.1163/156855394X00013.

8. Banavar R, Dey B. Stabilizing a flexible beam on cart: distributed port-Hamiltonian approach. Journal of Nonlinear Science. 2010;20(2):131-151. Available from: https://doi.org/10. 1007/s00332-009-9054-1.

9. Dadfarnia M, Jalili N, Xian B, Dawson MD. Lyapunov-based vibration control of translational Euler-Bernoulli beams using the stabilizing effect of beam damping mechanism. Journal of Vibration and Control. 2004;10(7):933-961. Available from: https://doi.org/10.1177/1077546304042070.

10. He W, Ge SS. Vibration control of a flexible beam with output constraint. IEEE Transactions on Industrial Electronics. 2015;62(8):5023-5030. Available from: https://doi.org/10. 1109/TIE.2015.2400427.

11. Yigit A, Scott RA, Ulsoy GA. Flexural motion of a radially rotating beam attached to a rigid body. Journal of Sound and Vibration. 1988;121(2):201-210. Available from: https://doi.org/ 10.1016/S0022-460X(88)80024-5.

12. Wu CC. Free vibration analysis of a free-free Timoshenko beam carrying multiple concentrated elements with effect of rigidbody motions considered. Journal of Sound an Vibration. 2019;445:204-227. Available from: https://doi.org/10.1016/j. jsv.2018.12.019.

13. Altunisik A, Okur FY, Kahya V. Vibrations of a box-sectional cantilever timoshenko beam with multiple cracks. International Journal of Steel Structures. 2019;19(2):635-649. Available from: https://doi.org/10.1007/s13296-018-0152-5.

14. Shin HC, Choi SB. Position control of a two-link flexible manipulator featuring piezoelectric actuators and sensors. Mecha- tronics. 2001;11(6):707-729. Available from: https://doi.org/ 10.1016/S0957-4158(00)00045-3.

15. Matsuno F, Ohno T, Orlov VY. Proportional derivative and strain (PDS) boundary feedback control of a flexible space structure with a closed-loop chain mechanism. Automatica. 2002;38(7):1201-1211. Available from: https://doi.org/10. 1016/S0005-1098(02)00013-4.

16. Shan J, Liu HT, Sun D. Slewing and vibration control of a single-link flexible manipulator by positive position feedback (PPF). Mechatronics. 2004;15(4):487-503. Available from: https://doi.org/10.1016/j.mechatronics.2004.10.003.

17. Fei J. Active vibration control of flexible steel cantilever beam using piezoelectric actuators. Proceedings of the 37th Southeastern Symposium on System Theory 2005, Tuskegee, AL, USA, USA . 2005; p. 35-39.

18. Aphale SS, Andrew J, Fleming J, Moheimani SOR. Integral resonant control of collocated smart structures. Smart Materials and Structures. 2007;16(2):439-446. Available from: https://doi.org/10.1088/0964-1726/16/2/023.

19. Omidi E, Mahmoodi SN, Shepard WS. Multi positive feedback control method for active vibration suppression in flexible structures. Mechatronics. 2016;33:23-33. Available from: https://doi.org/10.1016/j.mechatronics.2015.12.003.

20. Singer NC, Seering WP. Preshaping Command Inputs to Reduce System Vibration. Journal of Dynamic Systems, Measurement, and Control. 1990;112(1):76-82. Available from: https://doi.org/10.1115/1.2894142.

21. Singh T. Pole-Zero, Zero-Pole canceling input shapers. Journal of Dynamic Systems Measurement and Control-Transactions of the ASME. 2011;134(1):011015-011025. Available from: https://doi.org/10.1115/1.4004576.

22. Singhose W, Seering W, Singer N. Residual vibration reduction using vector diagrams to generate shaped inputs. Journal of Mechanical Design. 1994;116:654-659. Available from: https: //doi.org/10.1115/1.2919428.

23. Nguyen QC, Ngo HQT. Input shaping control to reduce residual vibration of a flexible beam. Journal of Computer Science and Cybernetics. 2016;32(1):75-90. Available from: https:// doi.org/10.15625/1813-9663/32/1/6765.

24. Sadat-Hoseini H, Fazelzadeh SA, Rasti A, Marzocca P. Final approach and flare control of a flexible aircraft in crosswind landings. Journal of Guidance Control and Dynamics. 2013;36(4):946-957. Available from: https://doi.org/10.2514/ 1.59725.

25. Zhu Q, Yue JZ, Liu WQ, Wang XD, Chen J, Hu GD. Active vibration control for piezoelectricity cantilever beam: an adaptive feedforward control method. Smart Materials. 2017;26(4). Available from: https://doi.org/10.1088/1361-665X/aa64c6.

26. Sahinkaya MN. Input shaping for vibration-free positioning of flexible systems. Proceedings of the Institution of Mechanical Engineers, Part I: Journal of Systems and Control Engineering. 2001;215(5):467-481. Available from: https://doi.org/10.1177/ 095965180121500504.

27. PI - Solution for precision motion and positioning," Physik Instrumente (PI) GmbH \& Co. KG, [Online]. [Accessed 20 January 2020];Available from: https://www.physikinstrumente.com/en/applications/ automation/smarter-motion-positioning/?utm_medium= Video\&utm_source=PI-Youtube\&utm_campaign=Input\% 20Shaping\%20for\%20Vibration\%20Free\%20Motion.

28. Pham PT, Nguyen QC. Dynamic model of a three-dimensional flexible cantilever beam attached a moving hub. Proceedings of 11th Asian Control Conference, Gold Coast, Queensland, Australia. 2017;p. 2744-2749. Available from: https: //doi.org/10.1109/ASCC.2017.8287611.

29. Ray BE, George TL. CRC Handbook of Tables for Applied Engineering Science, Boca Raton, Florida,: CRC Press, Inc. 1973;. 


\title{
Điều khiển hệ dầm công xôn mềm có bệ gá di động bằng phương pháp input shaping
}

\author{
Vũ Nguyễn Trí Giang1 , Phạm Phương Tùng² ${ }^{2}$ Nguyễn Quốc Chí ${ }^{1, *}$
}

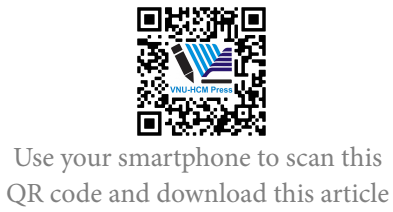

${ }^{1}$ Bộ môn Cơ điện tủ, Trường Đại học Bách khoa - Đại học Quốc gia Thành phố Hồ Chí Minh

${ }^{2}$ Khoa kỹ thuật Cơ khí, Đại học Quốc gia Pusan

Liên hệ

Nguyễn Quốc Chí, Bộ môn Cơ điện tử,

Trường Đại học Bách khoa - Đại học Quốc gia Thành phố Hồ Chí Minh

Email: nqchi@hcmut.edu.vn

Lịch sử

- Ngày nhận: 01-10-2019

- Ngày chấp nhận: 30-01-2020

- Ngày đăng: 16-8-2020

DOI : 10.32508/stdjet.v3i2.605

\section{Check for updates}

\section{Bản quyền}

๑) ĐHQG Tp.HCM. Đây là bài báo công bố mở được phát hành theo các điều khoản của the Creative Commons Attribution 4.0

International license.

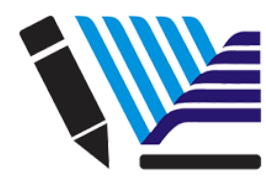

VNU-HCM Press

\section{TÓM TẮT}

Giới thiệu: Dầm công xôn là một kết cấu phổ biến trong các kỹ thuật, với chỉ một đầu được gắn cứng. Kết cấu này có thể được dùng để mô tả một cánh tay robot, với độ cứng lớn để đảm bảo độ cứng vững và ổn định của hệ thống. Một dầm công xôn mềm cung cấp một kết cấu nhẹ và hiệu quả chi phí, nhưng gây ra dao động dưới chuyển động tốc độ cao. Trong bài báo này, chúng tôi hướng đến việc điều khiển dao động của thanh dầm mềm được gắn trên một bệ gá có chuyển động thẳng. Phương pháp: Mô hình toán học của dầm công xôn mềm được biểu diễn bằng các phương trình vi phân đao hàm riêng (PDE-partial differential equation). Mồ hình được xấp xỉ bằng phương pháp Galerkin với kết quả là một mô hình biểu diễn bằng một hệ phương trình vi phân thông thường (ODE-ordinary differential equation). Phương pháp thực nghiệm được sử dụng để xác định các thông số chưa biết của hệ thống. Mô hình ODE tạo điểu kiện cho thiết kế ba giải thuật điêu khiển input shaping: (i) Zero-Vibration, (ii) Zero-Vibration-Derivative, và (iii) Zero-Vibration-Derivative-Derivative, được dùng để di chuyển dầm công xôn mềm đến vị trí mong muốn và giảm thiểu dao động. Kết quả và kết luận: Mô hình động lực của hệ được thiết lập với các phương trình vi phân thông thường. Các thông số chưa biết được xác định bằng thực nghiệm. Các bộ điều khiển khác nhau được thiết kế để khử dao động của thanh dầm. Quá trình mô phỏng dự đoán đáp ứng động lực học để xác minh độ hiệu quả của các bộ điều khiển bằng phương pháp số. Thực nghiệm chỉ ra sự hợp lệ của mô hình toán thông qua sự thống nhất của dữ liệu mô phỏng và thực nghiệm và sự hiệu quả của các bộ điều khiển với hệ thống thực. Những bộ điều khiển này có một ưu điểm như: không cần gắn thêm thiết bị; bộ điều khiển chuyển động không bị tác động nên các bộ điều khiển này có thể áp dụng với nhiều hệ thống có sẵn.

Từ khoá: Dầm công xôn mềm, phương pháp Galerkin, input shaping, khử dao động
Trích dẫn bài báo này: Giang $V \mathrm{~N} T$, Tùng $\mathrm{P} P, C$ í $\mathrm{N} Q$. Điều khiển hệ dầm công xôn mềm có bệ gá di động bằng phương pháp input shaping. Sci. Tech. Dev. J. - Eng. Tech.; 3(2):416-424. 